\title{
Autonomy, intimate partner violence, and maternal health-seeking behavior: Findings from mixed-methods analysis in Kenya
}

Charlotte E. Warren

Population Council

Pooja Sripad

Population Council

Charity Ndwiga

Population Council

Follow this and additional works at: https://knowledgecommons.popcouncil.org/departments_sbsr-rh

Part of the Demography, Population, and Ecology Commons, Domestic and Intimate Partner Violence Commons, Family, Life Course, and Society Commons, Gender and Sexuality Commons, International Public Health Commons, Maternal and Child Health Commons, and the Medicine and Health Commons How does access to this work benefit you? Let us know!

\section{Recommended Citation}

Warren, Charlotte E., Pooja Sripad, and Charity Ndwiga. 2019. "Autonomy, intimate partner violence, and maternal health-seeking behavior: Findings from mixed-methods analysis in Kenya," Ending Eclampsia Country Brief. Washington, DC: Population Council. 


\section{ENDING Eclampsia}

Autonomy, Intimate Partner Violence, and Maternal Health-Seeking Behavior: Findings from MixedMethods Analysis in Kenya

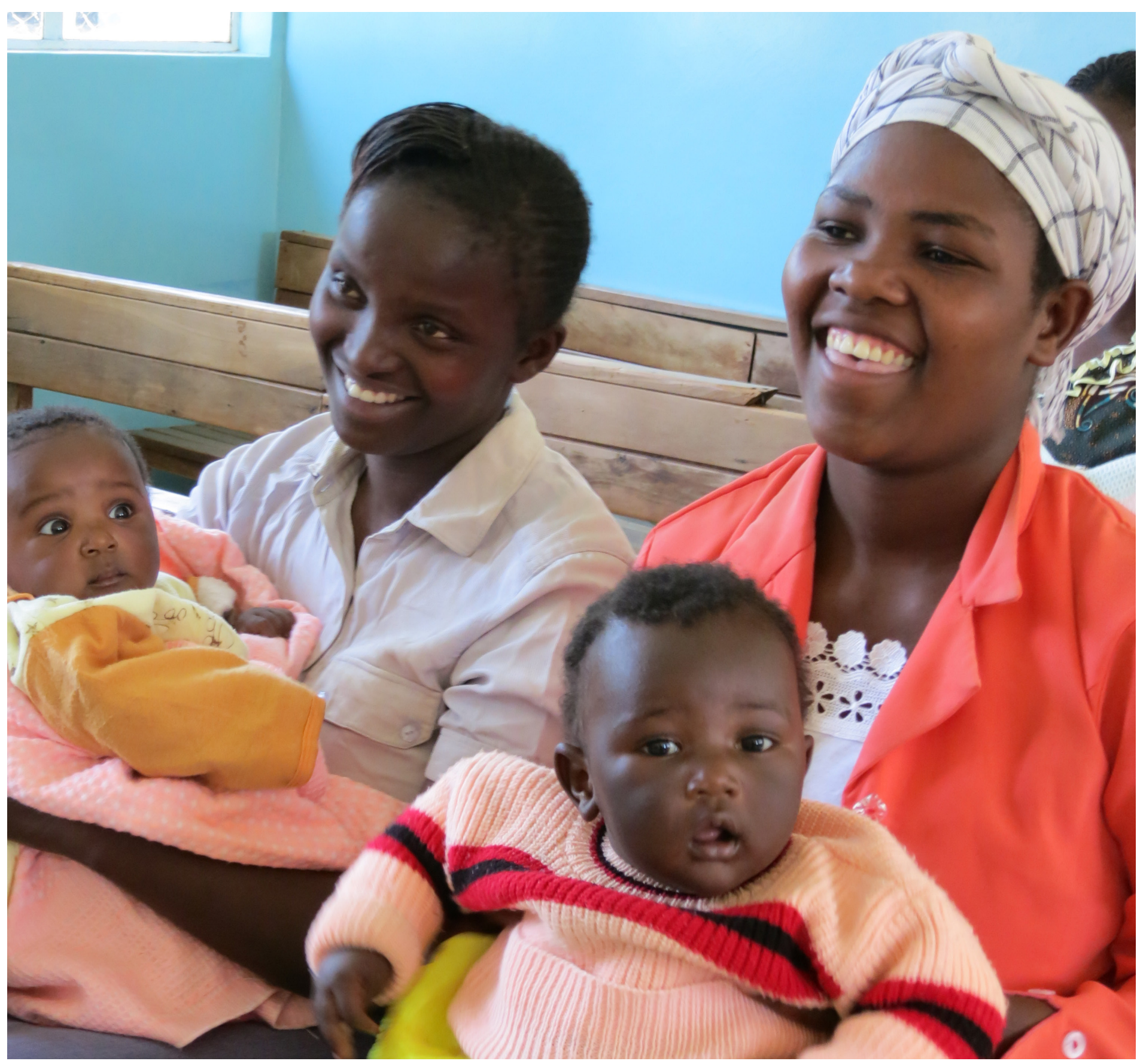

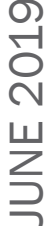

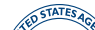

USADD (1.110. Made possible by the generous support of the American people through the United States Agency for International Development (USAID).
The Population Council conducts research and delivers solutions that improve lives around the world. Big ideas supported by evidence: It's our model for global change. popcouncil.org

(c) 2019 The Population Council, Inc

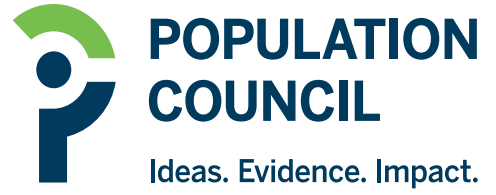




\section{BACKGROUND}

Gendered norms and discriminatory practices often limit women's decision-making power, which over time can lead to social norms that systematically disadvantage women.

Aspects of empowerment, a multi-faceted construct, were explored in a global evaluation of Demographic and Health Survey (DHS) data that measured how gendered social norms influenced maternal health-seeking behaviors.

Analysis specifically explored associations of women's autonomy and acceptability of intimate partner violence against women (IPVAW) on antenatal care (ANC) use and facility delivery in 63 low- and middle-income countries. Service utilization is positively associated with increased autonomy and negatively associated with increased acceptability of IPVAW, but variability exists across countries and regions. There is need to explore complexities of gender in specific contexts.

In Kenya, maternal health-seeking behaviors are influenced by numerous interrelated factors. Little research exists on how gender dynamics and norms, including acceptability of various forms of IPVAW, may influence women's decision-making autonomy, health-seeking behavior, and overall well-being.

The purpose of this study was to explore the relationship between women's autonomy and acceptability of IPVAW and two primary maternal health care utilization outcomes: ANC use and facility delivery.

This brief highlights quantitative and qualitative findings on the relationship between women's autonomy and IPVAW acceptability and maternal health seeking behaviors in Kenya.

\section{METHODS}

We applied a mixed methods approach to explore gender dynamics drawing on a secondary analysis of aggregate DHS data in Kenya from 2003 to 2014 and 16 in-depth interviews with women who had experienced and survived pre-eclampsia in Kakamega and Kitui counties between 2016 and 2017.

Scales developed for women's autonomy (6-item) and acceptability of IPVAW (5-item) indicate women's contribution to decision-making around various aspects of their lives and accepting attitudes toward a husband beating his wife for different reasons.

Multivariable logistic regressions estimated associations between these scores and the primary outcomes, controlling for age, wealth, education, marital status, birth order, child sex, urban/rural residence, and quality of care at the individual level and average wealth and educational attainment at the cluster level.

Qualitative analyses involved transcription and translation of interviews, applying an inductively derived codebook using NVivo, and triangulating findings from two counties with DHS results.

\section{RESULTS}

Combined Kenya DHS data from the 2003, 2008, and 2014 surveys yielded a sample of 22,590 women and found that 59\% of women delivered their last birth in a facility and $4.7 \%$ received their recommended eight ANC visits (Table 1).

Compared to global maternal health-seeking behaviors, women in Kenya are less likely to deliver in facilities and receive their eight recommended ANC visits ( $60 \%$ and $17 \%$ of women globally, respectively). Tables 2 and 3 describe the child-level and quality covariates. 
Table 1. Descriptive Statistics, Mother-Level Outcomes and Covariates, Kenya 2003-2014

\begin{tabular}{|c|c|c|c|c|c|}
\hline & Mean & SD & No. Cases & Min & Max \\
\hline \multicolumn{6}{|l|}{ Mother-Level Outcomes } \\
\hline Delivery in a health facility (1 = yes) & 0.588 & & 13,283 & & \\
\hline WHO Recommended 8 ANC Visits (1 = yes) & 0.047 & & 1,062 & & \\
\hline \multicolumn{6}{|l|}{ Mother-Level Covariates } \\
\hline Wealth, quintiles & 3.021 & 1.451 & & 1 & 5 \\
\hline Maternal education, none (1=yes) & 0.109 & & 2,462 & & \\
\hline Maternal education, primary (1=yes) & 0.574 & & 12,967 & & \\
\hline Maternal education, secondary (1=yes) & 0.239 & & 5,399 & & \\
\hline Maternal education, higher (1=yes) & 0.078 & & 1,762 & & \\
\hline Maternal age, years & 28.491 & 6.732 & & 15 & 49 \\
\hline Marital status (1=married) & 0.748 & & 16,897 & & \\
\hline Urban (1=yes) & 0.321 & & 7,251 & & \\
\hline \multicolumn{6}{|l|}{ Cluster-Level Covariates } \\
\hline Average wealth, quintiles & 2.995 & 1.235 & & 1 & 5 \\
\hline Average education, highest level & 1.272 & 0.515 & & 0 & 3.8 \\
\hline
\end{tabular}

Table 2. Descriptive Statistics, Child-Level Covariates, Kenya 2003-2014

\begin{tabular}{|l|c|c|c|c|c|}
\hline \multicolumn{7}{|c|}{ Mean } & SD & No. Cases & Min & Max \\
\hline Child-Level Covariates & 3.334 & 2.302 & & 1 & 16 \\
\hline Birth order & 0.017 & & 384 & & \\
\hline Multiple birth (1 = yes) & 0.515 & & 11,634 & & \\
\hline Child sex (1 = male) & $\mathbf{2 2 , 5 9 0}$ & \\
\hline $\begin{array}{l}\text { N } \\
\text { Notes: Each observation corresponds to a birth. }\end{array}$
\end{tabular}

Table 3. Descriptive Statistics, Child-Level Covariates, Kenya 2003-2014

\begin{tabular}{|l|c|c|}
\hline & Mean & No. Cases \\
\hline Quality Covariates & 0.301 & 6,800 \\
\hline Checked weight at pregnancy (1 = yes) & 0.095 & 2,146 \\
\hline Checked height at pregnancy (1 = yes) & 0.551 & 12,447 \\
\hline Checked blood pressure at pregnancy (1 = yes) & 0.454 & 10,256 \\
\hline Took urine sample at pregnancy (1 = yes) & 0.511 & 11,543 \\
\hline Took blood sample at pregnancy (1 = yes) & 0.302 & 6,822 \\
\hline Told about pregnancy complications (1 =yes) & 0.120 & 2,711 \\
\hline Told where to go for complications (1 = yes) & 0.205 & 4,631 \\
\hline Health professional checked after delivery (1 = yes) & 0.317 & 7,161 \\
\hline Quality score (0 - 1, percent out of 8) & 0.333 & 7,522 \\
\hline Quality score, prenatal (0 - 1, percent out of 7) & $\mathbf{2 2 , 5 9 0}$ & \\
\hline $\mathbf{N}$ & & \\
Notes: Each observation corresponds to a birth. & & \\
\hline
\end{tabular}


In the Kenya sample, $39 \%$ of women report involvement in decision-making regarding their own health care utilization; 33\% are involved in household purchasing; and 38\% in visiting relatives. Overall, $34 \%$ of women in Kenya report involvement in any decision-making.

Relatedly, $19.5 \%$ of women believe that a husband is justified in beating his wife for at least one of several reasons (Table 4). Proportions of autonomy (measured using decision-making power as proxy) and IPVAW were lower in Kenya compared to global estimates $(40.1 \%$ and $24.8 \%$ of women globally, respectively).

Compared to global positive associations, in Kenya, increased women's autonomy increased the likelihood of facility delivery (Kenya OR: 1.218, Global OR: 1.3, $p<0.01$ ), but reduced the likelihood of receiving eight WHO-recommended ANC visits (Kenya OR: 0.613, Global OR: 1.4, p<0.01). Kenyan associations of IPVAW with health care service utilization were similar to global trends, but more pronounced.

Women in Kenya with higher IPVAW scores were less likely than women globally to deliver in facilities (Kenya OR: 0.758, Global OR:0.911, p<0.01) and less likely to reach eight ANC visits (Kenya OR: 0.662, Global OR: 0.797, p<0.01) (Table 5).

Qualitative data corroborate that acceptance of women's subordinate positions in households renders most unable to independently make health care-seeking decisions. Spouses/intimate partners, mothers-in-law, and other family members play critical roles in determining whether and/or where women seek skilled care for ANC, delivery, and postnatal care (PNC).

These relationships affect a woman's decisionmaking ability to adhere to treatment regimens and seek care, given her restricted ability to use her own or her family's money for transport or medications.

"My legs were swollen, I would feel dizzy, my father and brothers said it's because I am walking too much. My sister just said it is normal for a pregnant woman. I rested, it did not change, so I went [to the hospital] after about three days."

Pre-eclampsia survivor, Kitui

The emotional toll of gender dynamics during pregnancy and postnatally manifest in various ways. For example, spousal neglect caused a pregnant woman deep sadness, burdened her with balancing household needs and managing her pre-eclampsia, and disempowered her after the loss of her baby.

"My husband doesn't bring me to the hospital when I collapse [from pre-eclampsia symptoms]. He even goes away [woman cries] ... In fact, I had become used to living without him and taking care of all the financial matters, such as paying rent and buying food for the household... the baby died."

Pre-eclampsia survivor, Kakamega

Table 4. Distribution of Autonomy and Acceptability of IPVAW Covariates, Kenya 2003-2014

\begin{tabular}{|l|c|c|}
\hline \multicolumn{2}{|l|}{ Mean } & No. Cases \\
\hline Autonomy & 0.248 & 5,602 \\
\hline Respondent involved in decisions over money (1 = yes) & 0.390 & 8,810 \\
\hline Respondent involved in decisions over own healthcare (1 = yes) & 0.326 & 7,364 \\
\hline Respondent involved in decisions over household purchases (1 = yes) & 0.212 & 4,789 \\
\hline Respondent involved in decisions over daily purchases (1 = yes) & 0.376 & 8,494 \\
\hline Respondent involved in decisions over visiting relatives (1 = yes) & 0.508 & 11,476 \\
\hline Respondent involved in decisions over cooking food (1 = yes) & 0.343 & 7,748 \\
\hline Woman autonomy score (0 - 1, percent out of 6) & 0.215 & 4,857 \\
\hline Acceptability of IPVAW & 0.296 & 6,687 \\
\hline Beating justified if wife goes out without telling husband (1 = yes) & 0.225 & 5,083 \\
\hline Beating justified if wife neglects children (1 = yes) & 0.157 & 3,547 \\
\hline Beating justified if wife argues with husband (1 = yes) & 0.083 & 1,875 \\
\hline Beating justified if wife refuses sex (1 = yes) & 0.195 & 4,405 \\
\hline Beating justified if wife burns food (1 = yes) & $\mathbf{2 2 , 5 9 0}$ & \\
\hline Women's acceptability of IPVAW score (0 - 1, percent out of 5) & & \\
\hline N & & \\
\hline
\end{tabular}


Table 5. Odds Ratios of Facility Delivery and Antenatal Care Use, Kenya 2003-2014

\begin{tabular}{|c|c|c|}
\hline Variables & (1) Facility Delivery & $\begin{array}{l}\text { (2) Antenatal Care (WHO } \\
\text { Recommended } 8 \text { Visits) }\end{array}$ \\
\hline \multicolumn{3}{|l|}{ Main Exposures } \\
\hline Woman's autonomy score & $1.218(1.093-1.358)^{* * *}$ & $0.613(0.548-0.685)^{* * *}$ \\
\hline Women's acceptability of IPVAW score & $0.758(0.669-0.860)^{* * *}$ & $0.662(0.593-0.740) * * *$ \\
\hline \multicolumn{3}{|l|}{ Covariates } \\
\hline Wealth Quintile 2 & $1.496(1.335-1.676)^{* * *}$ & $1.068(0.970-1.177)$ \\
\hline Wealth Quintile 3 & $1.843(1.638-2.074)^{* * *}$ & $1.248(1.121-1.390) * * *$ \\
\hline Wealth Quintile 4 & $2.482(2.162-2.849)^{* * *}$ & $1.362(1.206-1.539)^{* * *}$ \\
\hline Wealth Quintile 5 & $3.084(2.542-3.741) * * *$ & $1.669(1.418-1.963)^{* * *}$ \\
\hline Education, Primary & $1.665(1.448-1.914)^{* * *}$ & $1.155(1.037-1.287)^{* * *}$ \\
\hline Education, Secondary & $2.822(2.394-3.327)^{* * *}$ & $1.387(1.215-1.582)^{* * *}$ \\
\hline Education, Higher & $5.965(4.495-7.915)^{* * *}$ & $2.915(2.413-3.520)^{* * *}$ \\
\hline Marital Status (1=yes) & $1.265(1.160-1.380)^{* * *}$ & $1.554(1.442-1.674)^{* * *}$ \\
\hline Birth Order & $0.786(0.765-0.808) * * *$ & $0.910(0.892-0.929)^{* * *}$ \\
\hline Child Sex (1 = male $)$ & $1.159(1.086-1.237)^{* * *}$ & $0.973(0.919-1.030)$ \\
\hline Urban $(1$ = yes $)$ & $1.352(1.186-1.542)^{* * *}$ & $1.059(0.961-1.167)$ \\
\hline Average wealth score & $1.297(1.203-1.399)^{* * *}$ & $0.979(0.924-1.038)$ \\
\hline Average schooling & $1.477(1.277-1.710)^{* * *}$ & $1.136(1.027-1.258)^{* *}$ \\
\hline \multirow[t]{2}{*}{ Quality score } & & $5.212(4.547-5.974) * * *$ \\
\hline & & $(4.547-5.974)$ \\
\hline Constant & $0.0907(0.0577-0.143)^{* * *}$ & $0.370(0.249-0.548)^{* * *}$ \\
\hline \multicolumn{2}{|l|}{$\begin{array}{l}\mathbf{N} \\
* * * p<0.01, * * p<0.05, * p<0.1\end{array}$} & 22,200 \\
\hline \multicolumn{3}{|c|}{$\begin{array}{l}\text { Notes: The unit of observation is the birth. Odds ratios are presented with } 95 \% \text { confidence intervals in the parentheses below. Delivery in a facili } \\
\text { (column 1) reports whether the mother delivered the birth in a health facility or not. ANC visits (column 2) reports whether the mother received } \\
\text { least } 8 \text { ANC visits for the birth. Results are from logistic regressions that include cluster, mother, birth, and quality of care controls. Cluster-lev } \\
\text { covariates are the average wealth index value of mothers in the cluster, and the average educational attainment of mothers in the cluster. Mothe } \\
\text { controls include the household wealth index (in quintiles), educational attainment of the mother (no education, primary, secondary, higher), age } \\
\text { the mother (in 5-year age groups), mother's marital status, and mother's place of residence (urban/rural). Birth level controls include birth orde } \\
\text { For Column 2, quality of care controls include the 7-point average quality score that was generated for the birth. Standard errors are clustered at th } \\
\text { primary sampling unit (DHS cluster) level. }\end{array}$} \\
\hline
\end{tabular}

Pregnancy-related expenses deplete families' financial resources, compelling some women to overwork to sustain their households. This influences pregnant women physically and mentally, challenging their ability to rest, receive adequate nutrition, adhere to medications, and maintain a peaceful and supportive home environment while preparing for birth.

Even when women receive ANC, feelings of loneliness and managing on one's own, derived from familial neglect, often intersect with poverty status as influences on service use.

"She [pregnant woman] has pressure [pre-eclampsia] and lacks peace at home due to arguments she has with her husband."

Pre-eclampsia survivor, Kakamega
"There was no one to take care of me; I just took care of myself.... Even when I was pregnant, I could not go near fire. I would feel dizzy, and I would stay hungry because of that. Everyone [family members] stood up and went their way, no one bothered."

Pre-eclampsia survivor, Kitui

\section{CONCLUSIONS \& RECOMMENDATIONS}

Quantitative and qualitative findings suggest that gender dynamics, alongside other cluster- and individual-level factors, affect women's empowerment to seek maternal health services in Kenya.

Incongruencies between the influence of decisionmaking capacity of Kenyan women with respect to their health, mobility, and use of household finances 
on maternal service use were observed across methods.

Concurrent household power dynamics and normalized IPVAW effects - that may manifest as familial neglect or psychosocial harm from argumentative intimate partner dynamics - limit women's ability to reach care.

The shared experience of IPVAW during pregnancy has additional implications for adverse outcomes for those with complications like pre-eclampsia, including the emotional toll that may lead to mediumto long-term psychosocial repercussions.

We recommend further research around maternal mental health, including the role of neglect and feelings of isolation.

We further recommend explicit gender equitypromoting and socio-economically supportive policy and programming to enable women to mitigate consequences of IPVAW and empower them to use necessary maternal health care.

\section{REFERENCES}

1) Pooja Sripad, Charlotte E Warren, Michelle J Hindin, \& Mahesh Karra (2018). Assessing the role of women's autonomy and acceptability of intimate partner violence in maternal health-care utilization in 63 low- and middle-income countries. International Journal of Epidemiology, dyy299, https://doi.org/10.1093/ije/dyy299

\section{CONTACT}

Charlotte Warren, Senior Associate, Population Council

cwarren@popcouncil.org

Pooja Sripad, Associate, Population Council psripad@popcouncil.org

Charity Ndwiga, Program Officer, Population Council cndwiga@popcouncil.org

The Ending Eclampsia project seeks to expand access to proven, underutilized interventions and commodities for the prevention, early detection, and treatment of pre-eclampsia and eclampsia and strengthen global partnerships.

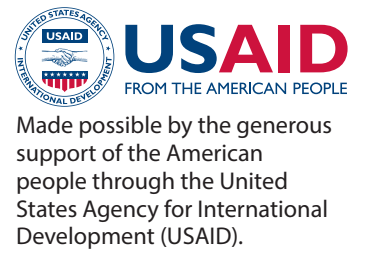

The Population Council conducts research and delivers solutions that improve lives around the world. Big ideas supported by evidence: It's our model for global change. popcouncil.org

(c) 2019 The Population Council, Inc.
POPULATION COUNCIL

Ideas. Evidence. Impact. 